\title{
Nephroblastoma in infants, 1969-75: variations in treatment and survival
}

\author{
C A STILLER, E L LENNOX
}

\section{Summary and conclusions}

In a series of 79 infants aged under 1 year with nephroblastoma diagnosed during 1969-75 all the patients underwent nephrectomy, $33(42 \%)$ received a course of radiotherapy, and $49(62 \%)$ received chemotherapy. The overall three-year survival rate for patients who survived at least one week after diagnosis was $65 \%$. The corresponding rate for infants with stage I tumours was $76 \%$. The survival rate in children with early-stage tumours was significantly higher in those who were treated by nephrectomy and chemotherapy alone compared with those who also received radiotherapy.

In a large proportion of cases nephrectomy and chemotherapy together constituted sufficient treatment for the cure of infants with nephroblastoma, and in some instances nephrectomy alone proved adequate. There was no general tendency for children under 1 year old to be unable to withstand chemotherapy.

\section{Introduction}

During 1962-9 in Great Britain the three-year survival rate for children with nephroblastoma aged under 1 year at diagnosis was $45 \%$, while the corresponding rate for children aged 1-15 years was $32 \%$ (Childhood Cancer Research Group, unpublished observations). During 1970-3, however, the three-year survival rates for the two age groups were respectively $61 \%$ and $57 \%{ }^{1}$ Thus the improvement in the rate for children aged over 1 year was substantially greater than that achieved for those aged under 1 year. These very young children were not included in the first MRC Nephroblastoma Study, which was in progress for most of that period, because of their better prognosis and the dangers of cytotoxic chemotherapy at this age. ${ }^{2}$

We examined records relating to infants diagnosed during 1969-75 to identify groups of patients with a notably better prognosis and to determine whether a higher survival rate was associated with any particular programme of treatment, since the treatment given to infants with nephroblastoma varied considerably.

\section{Patients and methods}

During 1969-75, 83 infants resident in Great Britain were notified to the National Cancer Registration Scheme as cases of nephroblastoma. The present series contained 79 infants, whose initial diagnosis of nephroblastoma was histologically confirmed by the hospital pathologist after nephrectomy. The four children not included in the series comprised two in whom the diagnosis was made radiologically and two whose tumours were diagnosed post mortem. Clinical information on all patients was derived from the hospital notes. Follow-up data were provided by the consultants or the patients' general practitioners. All of the children were followed up for at least three years from the time of diagnosis.

Seventy-three of the children had unilateral and six bilateral

Childhood Cancer Research Group, Department of Paediatrics, University of Oxford, Oxford OX1 $3 Q$ G

C A STILLER, BA, $M S C$, research officer

E L LENNOX, MB, CHB, research officer nephroblastoma at the time of diagnosis. Subsequent disease of the other kidney was noted in a further five children, at an interval of five to 28 months after the original diagnosis was made. Thus, in the present series of 79 children, $11(14 \%)$ at some time had disease of both kidneys. The proportion of patients with bilateral disease is considerably higher than the $4 \%$ found in a large series of children with nephroblastoma aged 0-14 years at diagnosis. ${ }^{1}$ The higher proportion of patients with bilateral tumours in the present series is consistent with earlier reports of a lower average age of patients with bilateral nephroblastoma. ${ }^{3}$

We adopted the clinical staging system used by Lennox et al. ${ }^{1}$ This is a slightly modified version of that used by the National Wilms' Tumour Study Group ${ }^{4}$ and in the MRC Nephroblastoma Study. ${ }^{2}$ The stage was determined by the surgeon and confirmed by the pathologist. The definitions of the five stages are (I) tumour confined to the kidney and completely resected; (II) tumour extended beyond the capsule of the kidney by local infiltration, extension along the renal vein, or involvement of the para-aortic nodes, but complete macroscopical removal achieved; (III) tumour extended beyond the capsule of the kidney and not completely resected or the operative field contaminated with tumour spilled at operation; (IV) haematogenous metastases (deposits in liver, lung, bone, brain, or other distant sites); and $(\mathrm{V})$ initial bilateral renal involvement.

Table I shows the distribution of children at the time of diagnosis by age and tumour stage. None of the patients in the series presented with distant metastases. In one 3-month-old baby not included in the series, however, postmortem examination showed previously undiagnosed bilateral nephroblastoma with multiple metastases in the liver and both lungs.

TABLE I-Age distribution of all patients by tumour stage

\begin{tabular}{|c|c|c|c|c|c|c|c|}
\hline \multirow{2}{*}{ Stage } & & & \multicolumn{4}{|c|}{ Age (months) } & \multirow{2}{*}{ Total } \\
\hline & & & $0-1$ & $2-6$ & $7-8$ & $9-11$ & \\
\hline $\begin{array}{l}\text { I } \\
\text { II } \\
\text { III } \\
\text { V }\end{array}$ & $\begin{array}{l}\cdots \\
\cdots \\
\cdots\end{array}$ & $\begin{array}{l}\ldots \\
\cdots \\
\cdots\end{array}$ & $\begin{array}{l}7 \\
3\end{array}$ & $\begin{array}{l}8 \\
4 \\
5\end{array}$ & $\begin{array}{r}17 \\
4 \\
1 \\
3\end{array}$ & $\begin{array}{r}19 \\
3 \\
2 \\
3\end{array}$ & $\begin{array}{r}51 \\
14 \\
8 \\
6\end{array}$ \\
\hline Tot & & & 10 & 17 & 25 & 27 & 79 \\
\hline
\end{tabular}

\section{Results}

\section{TREATMENT}

All 79 patients in the series underwent nephrectomy. Table II shows the combinations of treatment given in addition to surgery for all of the children. Eight of the 10 patients under 2 months at diagnosis were treated by nephrectomy alone. The youngest child to be given radiotherapy was aged 2 days at operation for a stage II tumour; a course of 2100 rads was given over four weeks, starting 12 days after nephrectomy. Eleven of the 19 patients for whom the total tumour dose was known received 2000-3000 rads, and the maximum total tumour dose known to have been administered was 3200 rads. The youngest

TABLE II-Treatment given in addition to nephrectomy

\begin{tabular}{cccccc}
\hline Stage & None & $\begin{array}{c}\text { Radiotherapy } \\
\text { alone }\end{array}$ & $\begin{array}{c}\text { Chemotherapy } \\
\text { alone }\end{array}$ & $\begin{array}{c}\text { Chemotherapy } \\
\text { and } \\
\text { radiotherapy }\end{array}$ & Total \\
\hline I & 18 & 6 & 17 & 10 & 51 \\
II & 3 & 2 & 4 & 5 & 14 \\
III & 1 & & 2 & 6 & 8 \\
V & 22 & 8 & 24 & 25 & 79 \\
\hline Total & 22 & & & & \\
\hline
\end{tabular}


patients for whom chemotherapy was included in the initial planned treatment were 2 months old at diagnosis. Of the 49 children who were given chemotherapy, $30(61 \%)$, including all those treated before 1972 , received actinomycin $\mathrm{D}$ alone. Eight $(16 \%)$ of the patients were given vincristine alone and $10(20 \%)$ both actinomycin $\mathrm{D}$ and vincristine. The remaining child was treated preoperatively for a massive nephroblastoma with cyclophosphamide, methotrexate, and vinblastine. Two children are known to have received only a single dose of actinomycin $\mathrm{D}$ at operation. The longest recorded course of chemotherapy was 33 months of actinomycin $\mathrm{D}$ and vincristine administered to a child with bilateral nephroblastoma. Because the duration of treatment was known for only $28(57 \%)$ of the 49 children we could not obtain a reliable estimate of the average duration of chemotherapy.

\section{SURVIVAL RATES}

Four ( $5 \%$ ) of the 79 children died within one week of diagnosis, the causes of death being renal thrombosis, septicaemia and aspiration pneumonia, pulmonary collapse, and peritonitis and meningitis. These four patients were not included in any analysis of survival rates, as they died too soon for the effects of treatment to be assessed.

Table III shows the three-year survival rates by tumour stage and initial treatment in the 75 children who survived at least one week after diagnosis. The overall three-year survival rate was $65 \%$. Only one of

TABLE III-Three-year survival of patients who survived for over one week, by tumour stage and initial treatment

\begin{tabular}{cccccc}
\hline Stage & Surgery & $\begin{array}{c}\text { Surgery }+ \\
\text { radiotherapy }\end{array}$ & $\begin{array}{c}\text { Surgery }+ \\
\text { chemotherapy }\end{array}$ & $\begin{array}{c}\text { Surgery }+ \\
\text { radiotherapy }+ \\
\text { chemotherapy }\end{array}$ & Total (\%) \\
\hline I & $12 / 17$ & $4 / 6$ & $14 / 16$ & $7 / 10$ & $37 / 49(76)$ \\
II & $1 / 2$ & $2 / 2$ & $3 / 4$ & $2 / 5$ & $8 / 13(62)$ \\
III & & & $0 / 1$ & $1 / 7(14)$ \\
Total $(\%)$ & $13 / 19(68)$ & $6 / 8(75)$ & $19 / 23(83)$ & $11 / 25(44)$ & $49 / 75(65)$ \\
\hline
\end{tabular}

the 49 children who survived to three years died subsequently: this was a child with bilateral nephroblastoma who survived 40 months after diagnosis. There was no significant difference in survival rates between patients with stage I and stage II tumours. Those with stage I or II nephroblastoma fared significantly better than those with stage III tumours (Fisher's exact test, $\mathrm{p}=0.005$ ). Of the children with stage I, II, or V tumours, those given chemotherapy alone in addition to surgery had a significantly higher survival rate than those given both chemotherapy and radiotherapy $\left(\chi^{2}=4.09 ; \mathrm{df}=1 ; \mathrm{p}<0.05\right)$. The only surviving child with a stage III tumour received both chemotherapy and radiotherapy.

Two of the patients aged under 2 months died postoperatively. The remaining six from this age-group who were given no further treatment after nephrectomy all survived.

All three of the three-year survivors among the children presenting with bilateral nephroblastoma had tumours removed from both kidneys either initially or at a subsequent operation. The survivors included both children with stage $\mathrm{V}$ tumours who were treated by surgery and chemotherapy alone. One of the patients who initially had a unilateral nephroblastoma and later developed a tumour in the other kidney also survived. This child underwent a right nephrectomy for a stage I tumour, then 11 months later had a tumour removed from the left kidney. Actinomycin D was administered at the time of the original surgery, and a course of vincristine was given after the later partial nephrectomy; no radiotherapy was given at any time.

\section{Discussion}

As cancer registration is not complete we cannot guarantee that this analysis included all infants with nephroblastoma first treated in Great Britain during the period under review. It has been reported, however, that one of the regional cancer registries received notifications for $93 \%$ of the residents in the local Regional Hospital Board area diagnosed as cases of childhood cancer during $1971-3,{ }^{5}$ and all of the 102 children resident in Great Britain who were included in the first MRC Nephroblastoma Study during 1970-4 had been notified to the National
Cancer Registration Scheme (Childhood Cancer Research Group, unpublished observations). On this evidence we assume that the vast majority of infants with nephroblastoma resident in Great Britain at the time of diagnosis during 1969-75 were included in our study.

The proportion of children surviving for three years after diagnosis of nephroblastoma who subsequently die from their disease is extremely small. ${ }^{1}$ We therefore concentrated on three-year survival rates in this report. The pattern of lower survival rates associated with higher-stage unilateral tumours reported in other series of children of all ages with nephroblastoma ${ }^{4}{ }^{7}$ was repeated in our series.

The three-year survival rate in children under 1 year of age with stage I or II nephroblastoma was $69 \%$. This compares favourably with the rate of $65 \%$ in children aged 1 year and over who were diagnosed as having tumours of equivalent stage during 1970-3 and were not included in the MRC Nephroblastoma Study. The rate achieved during the same period within the MRC study in patients with tumours of these stages was $81 \% .^{1}$ This is higher than the $69 \%$ survival in our series of children aged under 1 year, an age group which was excluded from the MRC trial because of its better prognosis. ${ }^{2}$ The three-year survival rate of $85 \%(17 / 20)$ in children in our series with stage I or II tumours who were given chemotherapy but no radiotherapy is similar to the $81 \%$ achieved in stage I and II patients in the MRC trial. Reports of other studies have suggested that radiotherapy may be omitted from the treatment of children with stage I nephroblastoma aged under 2 years, or even of any age, without adversely affecting survival ${ }^{4}$ ( $P$ A Voûte, $M-F$ Tournade, J Lemerle, A Rey, H J M Perry, F Sekaly; paper read at the 10th meeting of the International Society of Pediatric Oncology, 1978). The fact that three of the four patients with stage II tumours in the present series who were treated by surgery and chemotherapy alone were among the survivors shows that in some instances radiotherapy may also be unnecessary for the treatment of stage II tumours; further investigation of this is desirable but would require a much larger series of patients.

The much lower survival rate for patients with stage III nephroblastoma compared with stage I or II disease shows clearly that incomplete removal of the tumour considerably lessens the chances of survival, despite the administration of courses of radiotherapy and chemotherapy. This poorer record of survival compares with similar experience with older children with nephroblastoma. ${ }^{1}$

No conclusion may be drawn on the most effective treatment for stage III nephroblastoma, as only seven children with this tumour stage survived more than one week and all but one of the patients received both radiotherapy and chemotherapy. Interestingly, the sole long-term survivor from this group received a total tumour dose of only 1450 rads together with a two-year maintenance course of actinomycin D.

Only a small number of infants had bilateral nephroblastoma. These tumours are generally not extremely aggressive lesions, and correspondingly high survival rates may be expected. ${ }^{8}$ The survival rate in patients with bilateral tumours in the present series was higher than that in patients with unilateral stage III tumours. Although children with bilateral nephroblastoma form a heterogeneous group, the results presented above show clearly that the combination of surgery and chemotherapy alone is in some cases adequate for ensuring long-term survival.

The difference in survival rates between patients who were treated by chemotherapy in addition to nephrectomy and those who were treated by nephrectomy alone was not statistically significant. The actual proportion of survivors, however, was higher among the children given chemotherapy. At the very least, it is clear that there was a general tendency for children aged under 1 year to be able to withstand chemotherapy, though no patient aged under two months received this treatment. Among patients with stage I, II, or V tumours, which have a relatively good prognosis, the survival rate was lower in the children given both chemotherapy and radiotherapy than in those given chemotherapy alone. This difference might be 
accounted for by the perceived need for more intensive treatment for especially aggressive tumours, but in the absence of detailed histological reports on many of the cases this cannot be confirmed or refuted. Nevertheless, in a large proportion of cases nephrectomy and chemotherapy together evidently constitute sufficient treatment for the cure of infants with nephroblastoma. In the very youngest babies and some older patients nephrectomy alone has been followed by long-term disease-free survival.

We thank the many consultants and general practitioners who provided information on which this paper is based. We are grateful to Dr L M Kinnier Wilson for providing data from the Oxford Survey of Childhood Cancer, and to Mrs E M Roberts for her part in collecting the medical records and for secretarial help.

The Childhood Cancer Research Group is supported by the Department of Health and Social Security and the Scottish Home and Health Department. Collection of data was also supported by the Marie Curie Memorial Foundation.

\section{References}

1 Lennox EL, Stiller CA, Morris Jones PH, Kinnier Wilson LM. Nephroblastoma: treatment during 1970-3 and the effect on survival of inclusion in the first MRC trial. Br Med 7 1979; ii :567-9.

${ }^{2}$ Medical Research Council's Working Party on Embryonal Tumours in Childhood. Management of nephroblastoma in childhood. Arch Dis Child 1978;53:112-9.

3 Bond JV. Bilateral Wilms' tumour. Lancet 1975;ii:482-4.

${ }^{4}$ D'Angio GJ, Evans AE, Breslow N, et al. The treatment of Wilms' tumor. Cancer 1976;38:633-46.

${ }^{5}$ Leck I, Birch JM, Marsden HB, Steward JK. Methods of classifying and ascertaining children's tumours. Br $\mathcal{F}$ Cancer 1976;34:69-82.

6 Young JL, Heise HW, Silverberg E, Myers MH. Cancer incidence, survival and mortality for children under 15 years of age. New York: American Cancer Society, 1978.

7 Lemerle J, Tournade M-F, Gerard-Marchant R, et al. Wilms' tumor: natural history and prognostic factors Cancer $1976 ; 37: 2557-66$.

8 Bishop HC, Tefft M, Evans AE, D'Angio GJ. Survival in bilateral Wilms' tumor-review of 30 National Wilms' Tumor Study cases. 7 Pediatr Surg 1977;12:631-8.

(Accepted 28 September 1980)

\title{
Effect of guar crispbread with cereal products and leguminous seeds on blood glucose concentrations of diabetics
}

\author{
DAVID J A JENKINS, THOMAS M S WOLEVER, RODNEY H TAYLOR, HELEN M BARKER, \\ HASHMEIN FIELDEN, ALEXANDRA L JENKINS
}

\section{Summary and conclusions}

To compare the effect on blood glucose concentrations of guar incorporated into crispbreads with that of unprocessed high-fibre foods groups of four to six diabetics took a total of seven test breakfasts on separate days. By comparison with a breakfast of wholemeal bread and cheese, guar crispbread combined with bread reduced the area under the glucose response curve to $51 \%(p<0.05)$; bread and soya beans reduced the area to $65 \%(p<0.05)$ guar crispbread with soya beans to $25 \%(p<0.002)$; and soya beans with lentils to $29 \%(p<0.002)$. Porridge and cornflake breakfasts showed no difference.

The favourable results with leguminous seeds may not make such meals more acceptable than meals of guar products, but a combination of leguminous seeds and guar may allow smaller and more acceptable amounts of both to be used.

\footnotetext{
Department of the Regius Professor of Medicine, Radcliffe Infirmary, Oxford

DAVID J A JENKINS, DM, research associate

University Laboratory of Physiology, Oxford

THOMAS M S WOLEVER, MSC, research fellow

ALEXANDRA L JENKINS, research associate
Department of Gastroenterology, Central Middlesex Hospital, London NW10
RODNEY H TAYLOR, MRCP, Wellcome senior research fellow
HELEN M BARKER, BSC, SRD, research dietitian
HASHMEIN FIELDEN, SRN, research sister

\section{Introduction}

Studies on the use of purified fibre preparations in treating diabetes have often prompted comments unsupported by fact that using natural foods may be an effective and more palatable approach to this problem. ${ }^{12}$ To identify such foods $50-\mathrm{g}$ carbohydrate portions of a wide range of foods were taken by groups of healthy volunteers and the effect on the blood glucose response noted. ${ }^{3}$ These foods were then divided into two groups according to whether they caused small or large rises in blood glucose concentration. Foods were selected from each group and taken as breakfasts by diabetic volunteers so that their effects on blood glucose concentration could be studied and compared with the effect of a purified fibre product, guar crispbread. We report here the results.

\section{Methods}

Six diabetics (four women, two men; mean age $43+$ SEM 5 years; $99 \pm 3 \%$ ideal body weight; five receiving insulin 16-60 U/day and one controlled by diet alone) who had previously participated in a study testing the effect of guar and high-fibre foods on diabetic control were interested in testing the effect on their own blood glucose concentrations of taking meals of different composition and comparing this with the effect of guar. The food used had in earlier studies resulted in either large or small postprandial blood glucose responses in normal volunteers. ${ }^{3}$

The group met regularly on one or two Saturday mornings each month over four and a half months to test breakfasts in which a carbohydrate content equivalent to each subject's normal breakfast was derived from the following: wholemeal bread (88 SEM $13 \mathrm{~g}$ ) wholemeal bread $(46 \pm 8 \mathrm{~g})$ and guar crispbreads $(7 \pm 1$ crispbread) wholemeal bread $(46 \pm 8 \mathrm{~g})$ and soya beans $(91 \pm 11 \mathrm{~g})$; guar crispbread $(7 \pm 1$ crispbreads) and soya beans $(96 \pm 18 \mathrm{~g})$; soya beans $(75 \pm 6 \mathrm{~g})$ and lentils $(41 \pm 8 \mathrm{~g})$; cornflakes $(22 \pm 5 \mathrm{~g})$ and wholemeal bread $(45 \pm$ $10 \mathrm{~g})$; or porridge oats $(26 \pm 6 \mathrm{~g})$ and wholemeal spaghetti $(27 \pm 6 \mathrm{~g})$ 